\title{
Current Collegiate Experiences of Big-Time, Non-Revenue, NCAA Athletes
}

\author{
Amanda L. Paule \\ Bowling Green State University \\ Todd A. Gilson \\ Northern Illinois University
}

\begin{abstract}
Over the past 30 years experiences of collegiate athletes have been a major focus of scholarly research. Through well-known works, student-athletes' roles and personal development have been cornerstones of this new knowledge base (Adler \& Adler, 1991; Lapchick, 1987). However, an understanding of the big-time athlete who also participates in nonrevenue sports ${ }^{1}$ is grossly under-represented in the literature. Thus, the purpose of this study was to examine the benefits and challenges that athletes in these sports (e.g., tennis, soccer, golf, track and field, etc.) currently experience. Interviews were conducted with 30 collegiate athletes - who were chosen at random from a sample pool of 9,231 athletes around the country - that focused on the types of benefits and the specific challenges that these athletes face while attending college. Results revealed current benefits of being a big-time, nonrevenue college athlete were very heterogeneous with a total of 24 distinct themes mentioned. The most popular of these included: academic benefits, being on a team, learning life skills, improved time management, and tangible benefits such as equipment, facilities, scholarship and travel. Current challenges that athletes face were much more homogenous, as only three lower order themes received more than two responses: missing out on things in college, lack of free time, and being stereotyped. As a whole, most athletes believed the challenges they face were worth the perceived benefits; and thus, big-time, nonrevenue athletes do not receive an inferior overall college education experience (Potuto \& O'Hanlon, 2007).
\end{abstract}

Beginning in the 1980s researchers embarked on exploring the in-depth experiences of athletes. From a multitude of works (mainly focused on youth athletes), scholars and practitioners began to better understand the motives associated with sport participation. In particular, findings showed that individuals participate in sport because of fun, improvement of skills, increased health benefits, and achievement associated with competition (Feltz \& Ewing, 1987; Gill, Gross, \& Huddleston,

Paule is with the School of Human Movement, Sport, \& Leisure Studies, Bowling Green State University, Bowling Green, OH. Gilson is with the Department of Kinesiology and Physical Education, Northern Illinois University, DeKalb, IL. 
1983; Gould, Feltz, \& Weiss, 1985). Conversely, athletes who left sport commonly reported low levels of enjoyment, no opportunity to advance skills, and injury as significant factors (Burton, 1992; Gould, Feltz, Horn, \& Weiss, 1982; Lindner, Johns, \& Butcher, 1991).

Perhaps from this initial impetus, research examining the experiences of collegiate athletes flourished. Furthermore, in these subsequent studies, many research avenues developed. Specifically, lines of work including athletes' satisfaction (Killeya-Jones, 2005; Potuto \& O'Hanlon, 2007), socialization and resulting identity (Heller, Bloom, Neil, \& Salmela, 2005; Marx, Huffman, \& Doyle, 2008; Miller \& Kerr, 2002; Wilson \& Pritchard, 2005), personal development (Danish, Petitpas, \& Hale, 1990; Lapchick, 1987; Ryan 1989), academic performance (Adler \& Adler, 1985; Meyer, 1990; Richards \& Aries, 1999; Taylor, 1995), and the student-athlete role (Adler \& Adler, 1991; Meyer, 1990; Miller \& Kerr, 2002; Sack \& Thiel, 1985) were all explored. Much of this past work initially examined collegiate athletes in more traditional sports, such as football and basketball (see Adler \& Adler, 1991; Killeya-Jones, 2005; Sack \& Thiel, 1985; Taylor, 1995). This in itself is not surprising, or a cause for concern, because research has since progressed into studying sporting experiences of collegiate athletes who are females (Heller et al., 2005; Meyer, 1990; Weiss \& Barber, 1995), participate at the Division III level (Richards \& Aries, 1999; Sturm, Feltz, \& Gilson, 2010), are of minority decent (Sellers, Kuperminc, \& Damas, 1997), or participate in Special Olympics (Harada \& Siperstein, 2009). From the sample of studies cited here one could argue that most-if not all-important groups of collegiate/adolescent athletes have been examined and appropriate findings have been disseminated to scholars and practitioners.

However, even though the literature mentioned has examined "collegiate athletes' lives" from a multitude of perspectives, one segment of this population remains largely understudied - the big-time, nonrevenue collegiate athlete. These athletes participate in sports at some of the most prestigious and recognizable universities across the United States, but rarely receive any attention-outside of their inner circle-because the sports they play generate little income for the universities they attend. Examples of these sports include: golf, soccer, swimming and diving, and tennis, to name a few.

Albeit, some works have examined nonrevenue athletes (Potuto \& O'Hanlon, 2006, 2007; Ryan, 1989); however, the two articles by Potuto and O'Hanlon only gathered quantitative, Likert Scale data in response to various questions about academics, extracurricular activities, and future profession(s) and the latter-while utilizing a national sampling - is over 20 years old and may not be representative of today's collegiate athletes. Weiss and Barber (1995) offer tangential support for this latter assumption, as in their work they found new important sources of social support when comparing athletes' data separated by only one decade. Thus, it may be possible that collegiate experiences of big-time, nonrevenue athletes have changed in recent years.

The NCAA (2008) has attempted to fill the void of literature on nonrevenue producing athletes by conducted two studies, GOALS and SCORE, that examined current and former revenue and nonrevenue collegiate athletes, respectively. The document that presents the findings from these two studies combined the key findings from both of these studies. As a result, it is difficult to identify the specific 
experiences of the current nonrevenue athletes, and due to the fact that the SCORE study relied upon retrospective data it raises the question as to the accuracy of these findings. For instance, did the statements of the former athletes reflect how they felt when they were a collegiate athlete or has the time away from their sport impacted their perceptions? Therefore, while these studies are an important contribution to the field, they cannot be viewed as in-depth, representative analyses of current nonrevenue collegiate athletes.

Furthermore, the fact that big-time, nonrevenue athletes remain, in effect, absent from a large amount of the literature is troubling in light of recent recommendations calling for scholars and practitioners to pay closer attention to the lived experiences of student-athletes (Marx et al., 2008). Therefore, because the majority of collegiate athletes participate in nonrevenue sports, a current study-employing a national sampling - needs to be undertaken, by an entity other than the NCAA (NCAA, 2008), highlighting the present state of these athletes participating at large, Division I universities. Examining athletes in nonrevenue sports separately from their revenue sport counterparts is necessary because their experiences may be different from the sports - football, men's basketball, and at some institutions women's basketball — that traditionally receive a majority of the attention.

While many domains of collegiate-athlete life could be studied with big-time, nonrevenue athletes, to provide a foundation for future research-based on the previously cited literature-we felt that the next study involving this select group of participants should: (1) investigate big-time, nonrevenue athletes from a qualitative perspective; (2) select participants from a variety of sports based on a random sampling of said population across different geographical locations and conferences; and (3) broadly examine the benefits and challenges that these collegiate athletes face. For athletes, parents, and coaches work of this nature is extremely important because it is known that talent alone does not determine which individuals become elite performers. Instead, it is a combination of one's lived experiences, social structures, and sport characteristics that together, work in a hopefully, optimal way (Carlson, 1988).

\section{Method}

\section{Participants}

Participants for this study were current NCAA collegiate athletes at major Division I universities $(N=30)$. A total of nine, nonrevenue sports were represented (women's volleyball, $n=4$; track and field, $n=4$; swimming and diving, $n=4$; men's soccer, $n=3$; women's soccer, $n=3$; men's golf, $n=3$; women's golf, $n=$ 3 ; men's tennis, $n=3$; women's tennis, $n=3$ ), with the overall sample comprised of 20 females and 10 males.

\section{Instrumentation}

Interview Guide. Interviews conducted by the researchers were semistructured in nature and focused on the benefits and challenges big-time, nonrevenue athletes face while earning an education and competing in their sport. All interviews were identical with the researchers covering the same scripted set of questions in the 
same order with all participants. However, probes were used by the researchers to clarify participants' answers or to acquire more information regarding a specific topic (Berg, 2004; Patton, 2002).

\section{Procedures}

Following approval from the Institutional Review Board, a database was developed that included athletes from the previously listed sports in the Big 12, Big Ten, SEC, and PAC-10 conferences. Specifically, researchers gathered team roster information posted on university websites from every school, within each conference, that offered the sports of inquiry. Once the initial database was complete-with 9,231 current NCAA collegiate athletes - researchers then categorized participants by sport and designed ID numbers to each participant.

To achieve the most representative sample regarding the experiences of athletes in nonrevenue sports, researchers imposed two methodological strategies. First the target population of 30 participants was established per the distribution of athletes in each sport outlined in the participants section of this paper. Second, athletes were contacted-via e-mail—based on a numerical random sequence generator (http://www.random.org/sequences/) and then matched to the athlete's ID number. For example, in men's soccer, if the first three numbers from the sequence generator were: 17,98 , and 341, the athletes whose ID numbers matched the numbers generated were contacted for an interview. If only athlete \#17 responded willing to participate in the interview, the next two numbers from the same initial sequence were matched to athletes and those subsequent athletes were invited to participate in this study, excluding any athletes from a university in which another teammate already completed an interview. This process then continued until the "quota" of athletes was achieved for each sport.

During the initial e-mail contact, each athlete was informed about the goals, potential risks, time commitment necessary for the study (i.e., a 15-30 min phone interview), and asked to respond to the researchers if interested in participating. If a response was not received within one week, a short follow-up e-mail was sent relaying the same information. One week after the follow-up e-mail was sent, and if no response had been received, no further contact was made with the individual and the process was repeated with the next athlete from the generated sequence.

However, if an athlete did respond and agreed to participate in this study, the individual was sent a digital copy of the consent form, asked to read it over, and reply indicating if he/she agreed to participate in this study and if the interview could be digitally recorded. In addition, interviews were scheduled at a time convenient for both the participant and researcher and phone contact information was exchanged. On the previously agreed upon date and time, a researcher called the selected athlete and began the process of confidentially conducting the interview. Finally, during the actual interview, each participant was free to elaborate on a topic in the course of discussion once presented.

\section{Data Analysis}

After completion of each interview, digital voice recordings were transcribed verbatim by the researchers and assistants (Patton, 2002; Silverman, 2001). Next, 
the first and second authors worked through each interview to develop lower order themes using an inductive method (Patton, 2002). After reaching a consensus and identifying "repeated" themes, the research team was able to determine what athletes from big time, nonrevenue sports perceived as the benefits and challenges of participating in collegiate sport. The process of identifying themes continued until all the lower order themes were combined to form the higher order themes.

\section{Results}

As one might expect, higher-order themes regarding collegiate experiences of athletes could be categorized as either: (a) benefits of being a collegiate athlete, or (b) challenges faced while being a collegiate athlete. However, it was the frequency of specific examples and the detail used to describe experiences that enable this study to enlighten scholars and practitioners seeking to better understand the lives of the current big-time, nonrevenue collegiate athlete. The frequency and similarity of specific examples also lead the researchers to the understanding that these experiences were not isolated and could be attributed to athletes in other sports and other institutions.

\section{Benefits of Being a Collegiate Athlete}

Of the 30 athletes interviewed in this study, all mentioned at least one benefit they experienced while participating in athletics and many athletes discussed several benefits. Answers from the 30 athletes who participated in this study were spread between 24 distinct lower order themes. For the sake of brevity, only the top five lower order themes will be discussed, because at least five separate athletes spoke to each of these top five themes.

Academic Benefits. The most common benefit that athletes discussed in interviews was how participation in collegiate athletes had implicit academic benefits. In total 12 of the 30 athletes interviewed gave answers that were categorized into this theme. For example, Ellen (all names are fictitious), a female volleyball player in the Big-10 conference, discussed many of the privileges athletes at her school experience:

Benefits with school are very helpful, signing up for classes, of course we get the first priority, we actually get to take the classes when we want to. And...I meet with an athletic advisor every Monday; she's amazing and stresses upcoming exams and tests. I always have her telling me what to do for the week, what I have to start preparing for, and we talk about my grades and that's really helpful too.

Besides this substantial benefit, athletes also stated how being a collegiate athlete allows one access to tutors for help proofreading papers and assignments, the ability to get to know professors on a personal level because of their interest in the athlete's sport, and the ability to complete almost all academic business in private buildings, specifically for athletes. Cheryl, a female soccer player in the PAC-10 conference, noted how athletes at her school, “...get our own buildings... so you get internet and free printing." 
However, not all athletes focused on current academic benefits. Todd, a male soccer player in the Big-10 conference, spoke about how he perceived participating in collegiate athletics would help his future academic career:

When you look at it in the future, I'm trying to go to medical school. I've heard that being a student-athlete helps your chances of getting in because they've seen that you have had another responsibility and that you handled it and did well [and] really helps you get into medical school.

Clearly, from these selected statements representing the interview population, athletes in these big-time, nonrevenue sports understand the privileges afforded to them today and how these benefits may help them as they pursue their career after sport. These results contradict some of the findings from Adler and Adler (1985, 1991), in which collegiate athletes were shown to have a greater inclination toward their sport, when weighed against academic responsibilities. However, it is important to note that works by Adler and Adler focused on revenue generating sports, where individuals received much more exposure from their sport (e.g., basketball); and thus, may have greater time commitments when compared with athletes in the current study.

Time Management Skills. Six of the 30 athletes who participated in this study mentioned time management skills that they learned or used as a benefit of being a collegiate athlete. This lower order theme (along with themes of learning life skills and being on a team) represented the second most popular themes, in terms of frequency from respondents. Athletes who discussed time management highlighted how balancing school, life, and sport required planning. For instance, Leslie, a female soccer player in the Big-10 conference, stated:

Well, I definitely had to figure out time management real quick because you don't have 8 hours a day of free time like everybody else does. [Traditional students] go to class and they're done at 2 or whatever and have the rest of the day to do whatever they want. I've got 3 or 4 hours every day taken up by soccer...you come home from soccer and you have to do your homework, that's like the only time of the day you have to do it.

Andrew, a male tennis player in the Big-12 conference, continued to draw comparisons between athletes at his university and traditional students related to time management when he said, "[You] get more disciplined in your time management skills and you know that you have a certain window you have to do something in and it doesn't leave room for procrastination as much as a normal student."

Finally, Lori, a female track and field athlete in the Big-10 conference, provided a more developmental picture of how her time management skills became increasingly important as her status on the team improved:

A couple of weeks ago we went to Florida... well my first year I didn't, I wasn't really on the travel team my first year, and [impending travel] was not that much of a departure from [normal]. I mean would practice a little bit every day and it didn't seem like that much of a change. I was just running with the team opposed to running alone. But when I started to become competitive, that's when I think my focus changed and I just became more disciplined in all aspects of life and I learned how to better manage my time. 
As highlighted from these quotations, this necessary adoption of time management skills by athletes is essential because during competition season(s) athletes may be practicing for their sport up to 20 hours a week (NCAA, 2009).

Learning Life Skills. Along with the themes of time management and being on a team, six athletes' answers were categorized into this lower order theme. One athlete who went into great detail about the life lessons she has learned from her sport was Faith, a female swimmer in the PAC-10 conference:

[Sport has] taught me a lot of really important life lessons, like hard work paying off and goal setting being really important. Those are things that everyone says but until you really experience a life of setting very strategically placed goals you don't really understand what it's like. A lot of people get [life skills] through other things, through academics and through other extracurriculars, but I learned that through swimming. You learn about how far you can push people before they break. You learn about group dynamics. You learn about leadership.

Echoing Faith's comments about life skills was Lisa, a female track and field athlete in the Big-12 conference, when she stated:

[Sport] just helps me to stay focused... because I set goals in my sport and I have to set goals in my college career and in my actual professional career, so it's had a great impact on my life personally and I wouldn't trade it for anything.

The fact that several athletes spoke about values and life lessons they learned through their participation in sport is not surprising when examined from the sociological lens of the functionalist theory. Briefly, this theory contends that sport requires a great deal of consensus and cooperation from participants (Eitzen \& Sage, 2009). Therefore, life lessons can be an integral part of the sporting experience for individuals who compete with others toward a common goal, because each teammate should share common values to increase the group's chances of success.

Being On a Team. Six athletes also discussed how participating in collegiate sports gave them a chance to experience the benefit of interacting with teammates. Trenton, a male soccer player in the PAC-10 conference, mentioned, "Being part of a team, you know you can't really replicate that. And something about playing, just having your team is a really powerful sort of bond." For Katie, a female soccer player in the Big-10 conference, she considered her teammates to be a huge impact on her life, especially outside of sport:

Overall...to travel with the team...it's one of the greatest blessings. I've gained so many friends through [soccer]...my teammates I consider my sisters. Usually that's kind of rare to find because we spend so much time around each other that people would think we'd get sick of each other. But really, they are my sisters.

Erin, a female golfer in the Big-12 conference, added that when you are on a team, “...you're part of family. It's like you're a part of something before you even step onto the campus." Finally, Laura, a female tennis player from the PAC-10 conference, summed up athletes' perceptions related to this theme by stating, "Being together with other people that are going through the same thing is one 
of the advantages of being a collegiate athlete. You struggle together, you laugh together, [and] you cry together."

While there is no way to discern-based on the methodology of this studyperhaps one reason that only six athletes brought up being on a team as a benefit of collegiate athletics is because some athletes do not respect their teammates or coaches. Mitchell, a male golfer in the SEC conference, pondered this thought when answering during his interview:

I've been fortunate enough and blessed enough to be around quality coaches and teammates. Some people have bad experiences with teammates and some people have great experiences. I've been fortunate enough that every guy on our team, we all seem to get along; everybody respects our coaches. I don't know if that's the norm or not, I would think it is, but there are always horror stories where somebody doesn't like a coach or something like that.

Equipment, Facilities, Scholarship, and Travel. The final beneficial theme is the tangible benefits athletes receive while competing in their sport. Five athletes who shared their perceived benefits of being a collegiate athlete spoke to this theme. For example, Jenn, a female track and field athlete in the Big-12 conference, said, "I enjoyed getting my running shoes paid for. I know that sounds bad, but running shoes are fairly expensive we went through them so often, we ran so much."

While initially a somewhat unexpected theme, most athletes who discussed this theme during their interviews also justified this benefit because of other sacrifices they have to make while being a collegiate athlete. A case in point was Tony, a male swimmer in the Big-10 conference, who stated that he, "...get[s] to travel [but] I'm not on scholarship so there's no incentive there besides just being part of the team and getting to do what I like to do." Furthermore, Ali, a female volleyball player in the Big-10 conference, justified her scholarship when she said, "I got a full ride scholarship so you know, yeah I'm working because I'm playing a sport and that's considered a job pretty much..." Finally, Casey, a female track and field athlete in the Big-12 conference, also mentioned, "We get really nice training facilities - nicer than any I have ever seen - and the gear is always cool, but you put in the time and you get that."

These answers may offer an exciting a new avenue for future research, especially when nonrevenue sports are compared. In particular, Jenn was excited about receiving a new pair of running shoes for track and field, yet Allen-a tennis player in the PAC-10 conference-spoke about how his sport, "...[is] such a great environment to develop yourself; and economically, you get the top equipment, the top coaches, and it's really great to combine tennis and the college life [by knowing others] that might help you in the future." It is these distinctions between even nonrevenue sports that may serve to uphold class relations and economic inequality for collegiate athletes (Coakley, 2009).

\section{Challenges Faced While Being a Collegiate Athlete}

In contrast to the higher order theme of Benefits of Being a Collegiate Athlete, answers from athletes in this higher order theme were much more homogeneous. Specifically, while 29 of the 30 athletes in this study discussed challenges they face 
while being a collegiate athlete ( 1 athlete did not perceived any challenges), only three lower order themes received more than two responses.

Missing Out On Things In College. By far the most popular theme (in terms of number of responses) in this study was athletes' perceptions that sports caused them to miss out on variety of college experiences. A total of 16 athletes gave answers that were categorized into this lower order theme and Damien, a male tennis player in the Big-10 conference, shared his opinion as to why athletes experience this challenge, "You don't get some of the college experiences because you almost belong to the university a little bit. I mean you can't leave Thursday [before] spring break, you belong to the tennis team."

Because of the time commitments within collegiate sport, athletes felt as if they could not make time for things that were important to them. For example, Andrew, a male tennis player in the Big-12 conference, stated:

I've missed out on a lot of the normal college routine with not being able to do stuff with my friends in the afternoon. Instead of leaving early on a Friday afternoon for a long weekend, I have practice on Friday 'till the night time and then practice on Sunday.

However, the experiences that athletes "missed out on" while participating in collegiate athletics were not limited to purely social interactions with friends. Lori, a female track and field athlete in the Big-12 conference, talked about the professional opportunities she was not able to attend, "There's a professional club for actuaries, which I'm studying to become an actuary. It meets during practice times and there have been sessions with different employers and I've not been able to attend because it's always during practice." Lacey, a female golfer in the Big-12 conference, further confirmed this obstacle of joining extracurricular groups:

It's hard on the athletic side to explain to your coach that you have another meeting to go to and then on the opposite side it's the same old excuse, "I have practice" and that gets old. There are several organizations that I would love to be part of, but I can't.

These difficulties with living a "normal" college student life may eventually take a toll on athletes. Casey, a female track and field athlete in the Big-12 conference, spoke about how missing out on other college experiences affects her. "Sometimes I just want to experience regular college life without the athletic part. I live in an athletic dorm, my life is consumed with athletics, and sometimes I feel like I miss out on the college experience..." While comments like these-formed from perceptions of missing out on "regular" student life-seem to contradict the national study of collegiate athletes by Potuto and O'Hanlon (2007), Casey continued, "....but there are tons of perks and...I feel like the sacrifice is definitely worth what I have."

In addition, the perceptions of these athletes are in direct contrast to Finding \#4 reported in the NCAA's GOAL and SCORE studies (2008). The studies' findings stated that: The majority of student-athletes report that they are actively involved in their campus community outside of athletics and believe that their athletic participation has benefited them socially. The statements provided by multiple athletes in this study indicated that they felt as though they were missing out on 
campus activities and did not have much time outside of their sport to participate in academic organizations or socialize with nonathletes.

Lack of Free Time. As one might expect, big-time, nonrevenue athletes also discussed how a disadvantage of being a student-athlete was the lack of free time. Though tangential to the first theme in this section of missing out on things in college, this theme is distinct because it encompasses both activities that athletes want to do (e.g., socialize) and need to do (e.g., study). Nine athletes gave responses that were classified into this theme, including Laura, a female tennis player in the PAC-10 conference, who discussed how lack of free time impacted the choices she makes:

You're just constantly having to choose to do something I want to do or doing something that I have to do or that I need to do. After a while...in the back of your mind [you think] you should be doing something else, so it makes it really difficult to enjoy things that aren't school or tennis related.

When this concept is specifically related to schoolwork, Damien, a male tennis player in the Big-10 conference, who previously mentioned that he "belonged to the tennis team," stated, "I miss a lot of classes [and tennis] makes scheduling classes a little more difficult cause you don't want to miss any important classes on like Fridays and Mondays.' Furthermore, Jeff, a male golfer in the Big-12 conference, said, "It gets tough sometimes; you really don't have much free time. It is extremely time consuming and sometimes you just want to break."

To deal with these time pressures that big-time, nonrevenue athletes experience, the ability to learn and use time management skills becomes paramount. Kent, a male golfer in the SEC conference, stated that because he is an athlete:

There is a lot more time management. You have to plan out your day a lot more and make sure you are getting your studying in, you're getting your sleep in, because you are doing a lot throughout the day as opposed to the normal students who don't have to wake up for workouts and wake up for practice.

By establishing boundaries between "work" and "non-work" Kent is able to effectively manage his time, which can result in increased athletic success and psychological well-being (Forsyth \& Catley, 2007). Furthermore, to help athletes in this domain, some colleges have recently begun to enact in-service programs that focus on variety of life skills, including time management (Whitehead, 2009).

Being Stereotyped. Perhaps the lower order theme that was comprised of the most descriptive responses was the challenge of being stereotyped that athletes face. Seven of the 29 athletes who discussed challenges that athletes face shared their experiences with being stereotyped. Furthermore, as one might expect, several athletes made comments regarding being stereotyped in the classroom. Molly, a female swimmer in the Big-10 conference, spoke to this challenge directly:

A lot of my professors assume that if you are an athlete then you are going to take them for granted, not come to class, and just assume [you'll receive] a good grade for being an athlete. This isn't true... but that's the impression that they seem to give off for all of the student athletes. 
This stereotype may exist for a couple of reasons. First, athletes are in the public eye more than traditional students. Patti, a female volleyball player from the PAC-10 conference, made this contention when she spoke about bad experiences, "A couple of girls on my team have gotten in trouble for pictures being posted on websites. Just because they are athletes people will look through their Facebook pages and they'll put [their pictures] up on [different websites]." Additionally, this stereotype may also exist because big-time, revenue sports have given professors reasons to hold such stereotypes. While this study did not directly test this assumption, studies have noted that athletes in big-time, revenue sports have stronger athletic identities than student identities (Adler \& Adler, 1985, 1991), which prevent athletes from properly developing into college students (Marx et al., 2008). In addition, it appears that athletes in big-time, nonrevenue sports believe this to be true also, as highlighted by Cheryl, a female soccer player in the PAC-10 conference:

I don't want to biased, but football...I mean they don't do crap.... lot of them just kinda go through school and don't really set a good like athletic example [of] how [athletes] are because they think they're like God's gift to the school; when you have other student athletes working their butt off doing everything to graduate.

To combat these stereotypes that exist in the classroom, athletes mentioned several strategies they employ. Lisa, a female track and field athlete in the Big-12 conference, took a more traditional route when she said, "From the get-go, I try and look ahead at what my schedule is and what [professors] have posted on their syllabus. And try and tell them as soon as I can [that I will be traveling]." Faith, a female, swimmer in the PAC-10 conference, chose to mostly ignore these stereotypes, "You know at some point you sort of laugh it off; the athletes that have all of these other commitments are still beating [traditional students] in the classroom. I never really confront people about it." Finally, Molly, a swimmer who previously spoke about the stereotypes she experiences in the classroom took the unique approach of, "I try to not wear my apparel to class to show [professors] that I am a student athlete. That helps a little bit to take the attention off of me."

In this study all seven athletes who spoke about the stereotypes they experience because of their athletic participation were female, with most stereotypes dealing with academic perceptions. This result is not surprising considering that research has shown, compared with males, female athletes generally report higher levels of student identity and lower levels of athletic identity (Sturm et al., 2010). Thus, the female athletes in this study may value their education more than males; yet, be subjected to stereotypes that others form about all athletes through association with male athletes.

\section{Discussion}

The purpose of this study was learn about the current benefits and challenges that big-time, nonrevenue athletes face in their collegiate careers. Major impetuses for this study were the distinctions and suggestions from Marx et al. (2008). First Marx and colleagues made compelling argument that athletes in revenue generating sports (e.g., football and basketball) are inherently different from sports where 
generating revenue is not a primary purpose of the athletic department. Because of this distinction, it may be possible for athletes in these "smaller-scale" sports to be legitimate students in the classroom. Secondly, Marx et al., (2008) argue that scholars, practitioners, the NCAA, and university administrators have paid very little attention to the lived experiences and the process by which athletes are socialized when in the sport. The authors continued with suggestions based on their work, but like many other published papers, they fail to distinguish between the 17 revenue and nonrevenue sports included in their analyses.

In reviewing the benefits that athletes discussed, the notion of being on a team was important to athletes in this study and has been supported in other literature. Specifically, Munroe, Albinson, and Hall (1999), found that in interviews with athletes, the sport they participated in made them more motivated to attend school and feel more complete and satisfied in general. Thus, when athletes like Mitchell, a male golfer in the SEC conference, discuss their inability to join extracurricular organizations, he is quick to add, "But our team is like our own little fraternity. I get all the interaction and friendships that I think I would in another organization." Mitchell's response, as well as the responses from other athletes, emanate from a zero-sum world. Most individuals regret opportunities lost, but an important question is whether the athletes believe that the benefits of athletics participation outweighed their lost opportunities. Overwhelmingly, the responses indicated that the athletes did believe their athletic participation outweighed any perceived challenges to being an athlete.

Furthermore, the lower order themes in this study of athletes learning life skills and time management skills from sport support the findings from Potuto and O'Hanlon (2007) and Ryan (1989) in which athletes believed that sport participation instilled values independent of those received from other aspects of collegiate life, which traditional college students do not receive and may help explain why athletes perceive some social advantage because of their athletic participation (Sellers et al., 1997).

When examining the challenges that these big-time, nonrevenue athletes face, one might attain the belief that sports dictate too much of these athletes' lives. It is known that collegiate sport requires more time that any other extracurricular activity (Cantor \& Prentice, 1996). When reading quotes from Trenton, a male soccer player in the PAC-10 conference, who stated, "You don't always have time for what you want to do because you have a commitment to the team.... and it is a large commitment," this line of reasoning seems to be valid. However, many of the athletes interviewed made statements that the sacrifices were worth it or were the "cost of winning" in their sport. In addition, if coaches were to limit the amount of time dedicated to sport, this could be a detriment in itself, as Carlson (1988) found that lack of contact with coaches and continuity of training were the most distressing circumstances of elite tennis players.

The main limitation of this study is that while interviews were able to gain insight into collegiate athletes' lives, because of their focus these interviews were unable to explore interesting and unique answers that were tangential to the purposes of this study. For example, six of the seven athletes who mentioned being stereotyped as a challenge discussed this phenomenon in light of academics, either with professors or peers. However, Casey, a female track and field athlete in the Big-12 conference, spoke of a markedly different type of stereotype some female athletes experience: 
I never get accused of being this, but a lot of girls on my team get accused of being a lesbian. It's not just on the track and field team, it's on the volleyball team, the tennis team, it's every team; just being a women athlete. We are in the weight room with these guys [on the] same days and the sport does call for a lot of strength, so we are stronger than your average women; there is always that stereotype.

This quote in itself offers an interesting future direction for forthcoming scholars to broadly examine the stereotypes that big-time, nonrevenue athletes experience in all facets of their lives.

In addition, future work may wish to focus on the perceptions athletes have toward sport and their overall collegiate experience based on scholarship status. Since the majority of past work has been conducted with revenue sports (Adler \& Adler, 1991; Killeya-Jones, 2005; Sack \& Thiel, 1985; Taylor, 1995), where scholarships are the norm, instead of the exception, these works have most likely disproportionately sampled scholarships athletes who do not pay tuition and receive reimbursement for some living expenses. However, at the nonrevenue level, there are less scholarships (as a percentage of total team members) to distribute and experiences of these athletes may be different than their peers as they are required to participate in all athletic functions, obtain a degree, and pay for the privilege.

Finally, it is important to note that qualitative findings by nature are not meant to be representative of the greater population because of their restrictive sample size. While this study did employ a strong methodology in hopes of obtaining the most descriptive picture of the benefits and challenges current big-time, nonrevenue athletes face, it is possible that alternate data interpretations could be made regarding the gender of the participants and the institutions represented. However, from these interviews it was clear, that although these athletes face challenges of not being able to socialize as much as desired, constantly having to manage their time, and being stereotyped by peers and professors, most athletes believed these challenges were inherent in athletics and were secondary to the benefits they experience. Thus, we concur with the national study of NCAA Division I athletes by Potuto and O'Hanlon (2007), in which the authors stated, “...it appears that that those who believe that Division IA student-athletes are receiving an inferior overall college education experience need to re-assess their conclusions, or at least to consider how the student-athletes themselves evaluate that experience" (p. 966).

\section{Note}

1. While the terms "revenue" and "non-revenue" sports are used in this paper to categorize collegiate sports, it is important to note that not all "revenue" sports (e.g., football and basketball) are profitable at each NCAA institution.

\section{References}

Adler, P., \& Adler, P.A. (1985). From idealism to pragmatic detachment: The academic performance of college athletes. Sociology of Education, 58, 241-250.

Adler, P., \& Adler, P.A. (1991). Backboards and blackboards: College athletes and role engulfment. New York: Columbia University Press. 
Berg, B.L. (2004). Qualitative research methods for the social sciences (5th ed.). New York: Pearson.

Burton, D. (1992). Why young wrestlers "hang up" their singlet: An exploratory investigation comparing two models of sport attrition. Journal of Sport Behavior, 25, 145-163.

Cantor, N.E., \& Prentice, D.A. (1996, March). The life of the modern-day student athlete: Opportunities won and lost. Paper presented at the Princeton Conference on Higher Education, Princeton University, Princeton, NJ.

Carlson, R. (1988). The socialization of elite tennis players in Sweden: An analysis of the players' backgrounds and development. Sociology of Sport Journal, 5, 241-256.

Coakley, J. (2009). Sport and society: Issues and controversies (10th ed.). New York: McGraw Hill.

Danish, S.J., Petitpas, A.J., \& Hale, B.D. (1990). Sport as a context for developing competence. In T.P. Gullotta, G.R. Adams, \& R. Montemayor (Eds.), Developing social competency in adolescence (pp 169-194). Newbury Park, CA: Sage.

Eitzen, D.S., \& Sage, G.H. (2009). Sociology of North American Sport (8th ed.). Boulder, CO: Paradigm Publishers.

Feltz, D.L., \& Ewing, M.E. (1987). Psychological characteristics of elite young athletes. Medicine and Science in Sports and Exercise, 19, 98-105.

Forsyth, D.K., \& Catley, B. (2007). Time management and the full-time sportsperson: Increasing individual perceptions of time control. International Journal of Sports Science \& Coaching, 2, 305-317.

Gill, D.L., Gross, J.B., \& Huddleston, S. (1983). Participation motivation in youth sports. International Journal of Sport Psychology, 14, 1-14.

Gould, D., Feltz, D., Horn, T., \& Weiss, M. (1982). Reasons for attrition in competitive youth swimming. Journal of Sport Behavior, 5, 155-165.

Gould, D., Feltz, D., \& Weiss, M. (1985). Motives for participating competitive youth swimming. International Journal of Sport Psychology, 16, 126-140.

Harada, C.M., \& Siperstein, G.N. (2009). The sport experience of athletes with intellectual disabilities: A national survey of Special Olympics athletes and their families. Adapted Physical Activity Quarterly, 26, 68-85.

Heller, T.L., Bloom, G.A., Neil, G.I., \& Salmela, J.H. (2005). Sources of stress in NCAA Division I women ice hockey players. Athletic Insight: The Online Journal of Sport Psychology. Retrieved February 9, 2010, from http://www.athleticinsight.com/Vol7Iss4/ SourcesofStress.htm

Killeya-Jones, L.A. (2005). Identity structure, role discrepancies and psychological adjustment in male college student-athletes. Journal of Sport Behavior, 28, 167-185.

Lapchick, R.E. (1987). The high school athlete as the future college student-athlete. Journal of Sport and Social Issues, 1-2, 104-121.

Lindner, K., Johns, D., \& Butcher, J. (1991). Factors in withdrawal from youth sport: A proposed model. Journal of Sport Behavior, 14, 3-18.

Marx, J., Huffman, S., \& Doyle, A. (2008). The student-athlete model and the socialization of intercollegiate athletes. Athletic Insight: The Online Journal of Sport Psychology. Retrieved February 9, 2010, from http://www.athleticinsight.com/Vol10Iss1/StudentAthleteModel.htm

Meyer, B.B. (1990). From idealism to actualization: The academic performance of female collegiate athletes. Sociology of Sport Journal, 7, 44-57.

Miller, P.S., \& Kerr, G. (2002). The athletic, academic, and social experiences of intercollegiate student-athletes. Journal of Sport Behavior, 25, 346-368.

Munroe, K.J., Albinson, J.G., \& Hall, C.R. (1999). The effects of non-selection on first year female varsity athletes. AVANTE, 5, 63-81.

NCAA. (2008). The student-athlete perspective of the college experience: Findings from the NCAA GOALS and SCORE studies. Retrieved June 17, 2010, from http://www.ncaa. 
org/wps/portal/mne?WCM_GLOBAL_CONTEXT=/wps/wcm/connect/ncaa/NCAA/ Research/Student-Athlete+Well-Being/Student-Athlete_Experiences.html.

NCAA. (2009, August 1). 2009-10 NCAA division I manual: Constitution operating bylaws administrative bylaws. Retrieved March 4, 2010, from http://www.ncaapublications. com/Uploads/PDF/D1_Manual9d74a0b2-d10d-4587-8902-b0c781e128ae.pdf

Patton, M.Q. (2002). Qualitative research and evaluation methods (3rd ed.). Thousand Oaks, CA: Sage Publications.

Potuto, J.R., \& O'Hanlon, J. (2006). National study of student athletes regarding their experiences as college students. Retrieved June 17, 2010, from http://www.ncaa.org/ wps/wcm/connect/29f3e6804e0dacaaa060f01ad6fc8b25/2006_s-a_experience.pdf?M $\mathrm{OD}=\mathrm{AJPERES} \& \mathrm{CACHEID}=29 \mathrm{f} 3 \mathrm{e} 6804 \mathrm{e} 0$ dacaaa060f01 $\mathrm{ad} 6 \mathrm{fc} 8 \mathrm{~b} 25$

Potuto, J.R., \& O'Hanlon, J. (2007). National study of student-athletes regarding their experiences as college students. College Student Journal, 41, 947-966.

Richards, S., \& Aries, E. (1999). The Division III student-athlete: Academic performance, campus involvement, and growth. Journal of College Student Development, 40, 211-218.

Ryan, F.J. (1989). Participation in intercollegiate athletics: Affective outcomes. Journal of College Student Development, 30, 122-128.

Sack, A.L., \& Thiel, R. (1985). College basketball and role conflict: A national survey. Sociology of Sport Journal, 2, 195-209.

Sellers, R.M., Kuperminc, G.P., \& Damas, A. (1997). The college life experiences of African American women athletes. American Journal of Community Psychology, 25, 699-720.

Silverman, D. (2001). Interpreting qualitative data (2nd ed.). London: Sage.

Sturm, J. E., Feltz, D. L., \& Gilson, T. A., (in press). A comparison of athlete and student identity for Division I and Division III athletes. Journal of Sport Behavior.

Taylor, D.L. (1995). Academic preparation and subsequent performance of intercollegiate football players. Journal of College Student Development, 36, 444-451.

Weiss, M.R., \& Barber, H. (1995). Socialization influences of collegiate female athletes: A tale of two decades. Sex Roles, 33, 129-140.

Whitehead, B. (2009). National report. Interscholastic athletic administration, 36, 2.

Wilson, G., \& Pritchard, M. (2005). Comparing sources of stress in college student athletes and non-athletes. Athletic Insight: The Online Journal of Sport Psychology. Retrieved February 9, 2010, from http://www.athleticinsight.com/Vol7Iss1/StressAthletesNonathletes.htm 